\title{
Governamentalidade como ferramenta analítica: uma prática de pesquisa em educação especial
}

\author{
Márcia Lise Lunardi-Lazzarin* \\ Simoni Timm Hermes **
}

\begin{abstract}
Resumo: Este artigo objetiva mostrar como a governamentalidade constitui-se como uma ferramenta analítica na prática de pesquisa em Educação Especial. Situamos a problemática na condução das condutas dos docentes do Atendimento Educacional Especializado (AEE) nas escolas inclusivas. A partir de documentos legais e materiais didáticos relativos a essa formação continuada, em nível nacional e regional e das incursões nos Estudos foucaultianos em Educação, desenvolvemos o AEE como uma tecnologia de governamento docente, cuja estratégia de produção de uma subjetividade docente operacionaliza as táticas da docência no jogo de cada um e de todos, da docência como querer modificar-se e da docência como prática solidária. A partir dessa materialidade, a governamentalidade possibilita desenvolver um exercício de problematização numa proposta de análise das relações de poder.
\end{abstract}

Palavras-chave: Governamentalidade. Educação especial. Atendimento educacional especializado. Formação continuada de professores.

\section{Governmentality as an analysis tool: a research practice in Special Education}

\begin{abstract}
This paper aims at showing how governmentality works as an analysis tool in the research practice in Special Education. We have problematized the conduction of conducts of Specialized Educational Assistance (SEA) teachers in

* Doutora em Educação pela Universidade Federal do Rio Grande do Sul (UFRS). Professora Associada do Departamento de Educação Especial da Universidade Federal de Santa Maria (UFSM).E-mail: lunazza@gmail.com

** Mestre em Educação e Doutoranda em Educação pela Universidade Federal de Santa Maria (UFSM). Professora da UFSM.E-mail: simoni.hermes@ufsm.br
\end{abstract}


inclusive schools. From official documents and didactic materials related to that kind of continuing education in national and regional spheres, and also relying on the Foucauldian Studies in Education, we have regarded SEA as a technology governing teachers; its strategy for the production of teacher subjectivity operates teaching tactics in a game that affects each and everyone, regarding teaching as both a desire to change and a supportive practice. From that materiality, governmentality enables the development of a problematizing exercise in an attempt to analyze power relations.

Keywords: Governmentality. Special education. Specialized educational assistance. Continuing teacher education.

\section{Gubernamentalidad como una herramienta analítica: una práctica de investigación en Educación Especial}

Resumen: En este artículo se pretende mostrar cómo la gubernamentalidad se estableció como una herramienta analítica en la práctica de la investigación en Educación Especial. Situamos el problema de la conducción de la conducta de los profesores de Educación Especialista de Servicio (ESA) en las escuelas inclusivas. A partir de los documentos legales y materiales relacionados con este tipo de formación continuada a nivel nacional y regional y de las incursiones en los Estudios Foucaultianos en Educación, desarrolló la ESA como una tecnología de governamento de los maestros, la estrategia de producción de una subjetividad maestro operativas las tácticas de enseñanza el juego de todos y cada uno, de la enseñanza como queriendo ser modificados y la enseñanza como práctica conjunta. A partir de esta materialidad, la gubernamentalidad permite desarrollar un ejercicio de cuestionar una propuesta de análisis de las relaciones de poder.

Palabras clave: Gubernamentalidad. Educación especial, Educación especialista de servicio. Formación continuada de los maestros.

\section{Prática de pesquisa em educação especial: intenções}

A constituição do Atendimento Educacional Especializado (AEE) nas escolas comuns/regulares/inclusivas - serviço este destinado à complementação ou à suplementação da formação dos alunos com deficiência, 
transtornos globais do desenvolvimento e altas habilidades/superdotação - e os investimentos na formação continuada de professores que, pelo AEE, atuam nas salas de recursos multifuncionais, contextualizam o desenvolvimento de uma pesquisa concluída em nível de pós-graduação na linha de pesquisa "Educação Especial"', com o objetivo de compreender como, através do AEE, conduzimos as condutas docentes para atuarem nessas salas de recursos multifuncionais. Dessa forma, especificamente no cruzamento da Educação Inclusiva com a Educação Especial nessa prática de pesquisa, utilizamos os documentos legais e didáticos referentes à Rede Nacional de Formação Continuada de Professores na Educação Especial, bem como o Projeto Institucional e os Projetos Pedagógicos dos Cursos de Aperfeiçoamento em AEE de uma Instituição Federal de Ensino Superior do Estado do Rio Grande do Sul, para mapearmos as lógicas e as operações desse serviço da Educação Especial na contemporaneidade, analisarmos as relações entre o AEE e a Educação Inclusiva nas práticas neoliberais e problematizarmos o governamento docente na escola inclusiva.

Considerando isso, este artigo objetiva mostrar como a governamentalidade, noção cunhada por Michel Foucault a partir dos Cursos Em defesa da sociedade (2005), Segurança, território e população (2008a) e Nascimento da biopolítica (2008b), constitui-se como uma ferramenta analítica nesta prática de pesquisa em Educação Especial. Partimos do entendimento de que não se trata de esgotar os sentidos da governamentalidade, mas de operar na zona cinza, lançando olhares e operando com essa ferramenta no exercício de problematização do AEE como uma tecnologia de governamento docente, com estratégia e táticas

1 Trata-se da dissertação de Mestrado em Educação O Atendimento Educacional Especializado como uma tecnologia de governamento: a condução das condutas docentes na escola inclusiva, da autoria de Simoni Timm Hermes, sob orientação da Professora Dra. Márcia Lise Lunardi-Lazzarin, concluída em 2012, no Programa de Pós-Graduação em Educação - Mestrado, da Universidade Federal de Santa Maria (UFSM). 
específicas. Considerando que "a genealogia é cinza; ela é meticulosa e pacientemente documentária. Ela trabalha com pergaminhos embaralhados, riscados, várias vezes reescritos" (FOUCAULT, 2001, p. 15), zona cinza significa um trabalho de inspiração genealógica voltado às marcas e às lutas produzidas nos interstícios; da mesma maneira, ao movimento do pesquisador que recusa e problematiza constantemente uma identidade primeira, a supra-história, o lugar da verdade. Nesse sentido, tomamos a zona cinza para problematizar o lugar de verdade do AEE nas políticas públicas de Educação Especial, na formação continuada de professores e nas escolas inclusivas. A governamentalidade, "a maneira como se conduz a conduta dos homens, não é mais que uma proposta de grade de análise para essas relações de poder" (FOUCAULT, 2008b, p. 258), passa a ser entendida como uma ferramenta potente para operar com essa zona cinza na prática de pesquisa em questão.

Essa ferramenta analítica, no entendimento da noção de caixa de ferramentas de Foucault, rompe com os usos de uma teorização como causa e efeito, porque tomamos a governamentalidade como uma ferramenta que deve operar, produzir efeitos na e com a materialidade de pesquisa. Como expressa Deleuze, na conversa com Foucault intitulada Os intelectuais e o poder, em 02 de março de 1972, "uma teoria é como uma caixa de ferramentas. É preciso que sirva, é preciso que funcione. E não para si mesma. Não se refaz uma teoria, fazem-se outras; há outras a serem feitas" (FOUCAULT, 2001, p. 71). Para tal empreendimento, num primeiro momento, descrevemos a materialidade da prática de pesquisa que possibilitou a produção do AEE como uma tecnologia de governamento docente na contemporaneidade. Num segundo momento, tomamos o governamento dos homens através da racionalidade política neoliberal, na versão norte-americana, em suas relações com a tecnologia de governamento, a estratégia e as táticas dessa prática de pesquisa em Educação Especial. Entendemos, nesse sentido, a partir de Foucault, que as artes de governar, emergentes no século XVI, e a razão de Estado, racionalidade que se coloca como instrumento de inteligibilidade e de es- 
tratégia nas práticas de governamento, especificamente, pela emergência de um Estado governamentalizado, oferecem condições de possibilidade à formação continuada de professores do AEE e à organização da docência às escolas inclusivas.

\section{Prática de pesquisa em Educação Especial: materialidade}

A Educação Inclusiva, com políticas e práticas voltadas à mobilidade dos sujeitos no tecido social, e a Educação Especial, interessada nos sujeitos com deficiência, transtornos globais do desenvolvimento e altas habilidades/superdotação, movimentaram-se, nas últimas décadas, na constituição do AEE. Embora a Educação Especial, ao longo dos anos, tenha-se envolvido com a oferta de serviço educacional especializado, a partir da publicação da Política Nacional de Educação Especial na Perspectiva da Educação Inclusiva, da Resolução CNE/CEB n ${ }^{\circ}$ 4, de 02 de outubro de 2009, do Parecer CNE/CEB no 13, de 03 de junho de 2009 e do Decreto $\mathrm{n}^{\mathrm{o}} 7611$, de 17 de novembro de 2011, esta oferta ocorre prioritariamente na escola inclusiva.

Nesse sentido, entendemos que a inclusão escolar constitui-se como um dispositivo biopolítico (LOPES; VEIGA-NETO, 2007) que, numa política de produção e promoção da vida, torna-se capaz de gerenciar o risco, desenvolvendo ações de prevenção e controle dos fenômenos acidentais da população, como os desvios em relação à norma do público-alvo da Educação Especial, e gerar segurança na escola inclusiva e na sociedade contemporânea. Dessa maneira, a Educação Especial efetiva-se como o campo de saber e poder, digamos epistêmico, que, junto a outros como a Medicina Social, a Psicologia e suas derivações, a Pedagogia, opera nos processos de normalização, ou seja, nesse jogo do mais normal e do mais anormal, dos seus gradientes, a partir de uma norma que não existe a priori, nem permanece fixa, mas condicionada e produzida nas relações sociais. Por essas operações, a Educação Especial "não desaparece com as políticas de inclusão, pelo contrário, é utilizada e, de uma 
certa forma, reforçada para garantir o sucesso da inclusão" (LUNARDI, 2003, p. 186). A Educação Especial, então, trabalha em prol da inclusão escolar, na medida em que oferece condições de possibilidade ao AEE, seja na formação continuada de professores, seja nas escolas inclusivas.

Nessas condições de possibilidade, situamos a materialidade da pesquisa referida anteriormente. Nesta, constituímos duas etapas para mapear a formação continuada de professores e para explorar documentos legais e materiais didáticos relativos à proposição dessa formação de professores em AEE em nível nacional e regional. Dessa forma, desenvolvemos uma prática de pesquisa voltada à "Rede Nacional de Formação Continuada de Professores para a Educação Especial" e à "Instituição Federal de Ensino Superior - IFES”. Essas etapas, mesmo sendo caracterizadas e registradas em momentos distintos, integram-se naquilo que, na seção seguinte, produzimos como uma tecnologia de governamento.

Nesse sentido, na etapa "Rede Nacional de Formação Continuada de Professores para a Educação Especial”, realizamos uma pesquisa quadrimensal no Portal da Imprensa Nacional nos documentos publicados no Diário Oficial da União (DOU) de janeiro de 2007 a dezembro de 2011. Das 488 publicações relacionadas ao atendimento educacional especializado, 12 publicações, entre elas editais, planos plurianuais, programas de Governo, decretos, resoluções, portarias, foram tomadas para o entendimento da existência de uma Rede Nacional voltada à formação continuada de professores do AEE à escola inclusiva. Ainda, utilizamos a Coleção "A Educação Especial na Perspectiva da Inclusão Escolar", publicada pela Secretaria de Educação Especial (SEESP) em parceria com a Universidade Federal do Ceará (UFC), no ano de 2010. Esta Coleção contempla dez materiais didáticos denominados de "A escola comum inclusiva", "O atendimento educacional especializado para alunos com deficiência intelectual", "Os alunos com deficiência visual: baixa visão e cegueira", "Abordagem bilíngüe na escolarização de pessoas com surdez", "Surdocegueira e deficiência múltipla", "Recursos pedagógicos acessíveis e comunicação aumentativa e alternativa”, 
"Orientação e mobilidade, adequação postural e acessibilidade espacial", "Livro acessível e informática acessível", "Transtornos globais do desenvolvimento" e "Altas habilidades/superdotação". De maneira geral, esses materiais didáticos exploram o AEE na articulação entre a escola inclusiva e a Educação Especial, bem como os conhecimentos, os recursos, as técnicas, as atitudes a serem desenvolvidas pelo docente do AEE para atuar com a deficiência intelectual, a baixa visão e a cegueira, a surdez, a surdocegueira, a deficiência múltipla, a deficiência física, os transtornos globais do desenvolvimento e as altas habilidades/ superdotação na escola inclusiva.

Na etapa, "Instituição Federal de Ensino Superior - IFES", utilizamos o Projeto Institucional "Fundamentos para a implementação de uma política pública de formação continuada de professores na área da Educação Especial, na modalidade a distância, para ser implementado pelo Ministério da Educação (MEC), através da Secretaria de Educação Especial (SEESP)" e os Projetos Pedagógicos das cinco edições do Curso de Aperfeiçoamento em AEE, ofertadas de 2007 a 2011 aos professores das redes municipal e estadual de ensino no Estado do Rio Grande do Sul. Nessa etapa, tendo os registros de uma formação continuada de professores do AEE em nível regional, privilegiamos, como na Coleção da etapa anterior, as singularidades e as recorrências discursivas implicadas com lógica de conhecimentos, recursos, técnicas e atitudes do docente do AEE na escola inclusiva.

\section{Governamentalidade como ferramenta analítica: tecnologia de governamento, estratégia e táticas na formação continuada de professores}

Na prática de pesquisa em questão, tomamos o AEE como uma tecnologia de governamento docente, na medida em que deriva de um campo epistêmico, a Educação Especial, e trabalha dentro de um dispositivo de poder, a inclusão escolar. Nesse cruzamento da Educação 
Especial com a Educação Inclusiva, nesse interstício, nessa zona cinza, tecnologia de governamento corresponde aos "mecanismos através dos quais autoridades de vários tipos têm buscado moldar, normalizar e instrumentalizar a conduta, o pensamento, as decisões e aspirações de outros a fim de alcançar os objetivos que elas considerem desejáveis" (MILLER; ROSE, 1993, p. 82 apud TRAVERSINI, 2003, p. 41-42).

Na Política Nacional de Educação Especial, produzida em 1994, a Educação Especial complementava ou suplementava a escola regular, contudo, nos casos dos alunos com maior grau de comprometimento nos processos de aprendizagem e desenvolvimento, esse serviço educacional substituía o espaço-tempo comum/regular/inclusivo. O educador especial, com formação inicial ou com pós-graduação em Educação Especial, era eleito como o profissional da educação capaz de acompanhar esses sujeitos portadores de deficiência (física, sensorial ou intelectual), condutas típicas e altas habilidades, e propor, junto com outros especialistas, a inclusão ou não desses alunos nas salas regulares.

Com a Política Nacional de Educação Especial na Perspectiva da Educação Inclusiva, as legislações e as publicações do Ministério da Educação colocam o professor da sala regular como responsável pela formação desses alunos, bem como pelas redes a serem organizadas para acompanhar e intervir na vida desses sujeitos. A escola regular deve ser o lugar de aprendizagem e desenvolvimento dos sujeitos da Educação Especial, independente dos graus de comprometimento dos alunos que sempre terão à disposição o AEE. Assim, os professores, geralmente oriundos das salas regulares e não apenas a expertise da Educação Especial, são convidados a participar de formações continuadas que tratam da maioria dos desvios conhecidos e construídos na Modernidade, inclusive aqueles materializados na Rede Nacional de Formação Continuada de Professores para a Educação Especial, a fim de colaborar com o sucesso da inclusão escolar. Através desses cursos, esses professores apreendem e são apreendidos por uma estratégia e por táticas. Estratégia e táticas estas que servem no trabalho nas chamadas salas de recursos multifuncionais e 
que, ao mesmo tempo, inscrevem esse docente do AEE na racionalidade política neoliberal.

Antes de tramar as relações desta racionalidade política com a prática de pesquisa em Educação Especial, pontuamos os motivos que nos levam, diante de uma política de Estado, a Política Nacional de Educação Especial na Perspectiva da Educação Inclusiva, e os investimentos advindos da Política Nacional de Formação de Professores no nosso País, a proceder com o exercício de problematização acerca do neoliberalismo. Primeiramente, servimo-nos do entendimento de que o liberalismo, doutrina econômica do século XVIII, especialmente com as contribuições de Adam Smith, limita a ação do Estado, poderíamos usar a expressão horror ao Estado, para conseguir uma economia máxima, priorizando a propriedade privada e a garantia e a liberdade do uso do excedente da produção. Por sua vez, o neoliberalismo, emergente no século XX, pressupõe um Estado mínimo que trabalhe ao serviço da economia. Nesta, ao que nos interessa, as políticas de Estado não desaparecem, lembremos do governo de Fernando Henrique Cardoso (1995 - 2003), mas são gestadas pelo princípio de custo mínimo. O Estado passa a promover a economia, mercantilizando as relações, inclusive, as escolares. Então, num segundo momento, a ênfase do neoliberalismo nesta prática de pesquisa decorre do entendimento de sujeito econômico a partir de Foucault (2008a, 2008b) nessa racionalidade política. A mercantilização das relações implica que - para se tornar governamentalizável alvo e efeito do Estado, do mercado, o sujeito, seja o professor do AEE, seja o aluno da Educação Especial - precisa constituir-se dentro de uma economia, de uma lógica de consumo e concorrência. O Estado dessa racionalidade política neoliberal, dessa forma, minimiza seus custos porque, por fazer economia, produz sujeitos empresários de si, sujeitos solidários. Mais ainda, reduz este custo na educação, na medida em que investe na formação continuada de professores, neste caso, numa formação rápida e massiva.

Considerando esses motivos, o neoliberalismo, nas versões alemã e americana, refere-se aos modos de vida, às relações entre governantes e 
governados. Na versão americana, a que serve à prática de pesquisa em questão, encontra-se a Teoria do Capital Humano, derivada dos estudos de Theodore Schultz, em meados de 1950 a 1960. Nesse sentido, para Foucault (2008b, p. 301), essa forma de liberalismo "é toda uma maneira de ser e de pensar. É um tipo de relação entre governantes e governados, muito mais que uma técnica dos governantes em relação aos governados". Trata-se, então, de, nesses estudos da Teoria do Capital Humano, tomar o investimento no capital humano como fonte de renda futura. Desse entendimento derivam as noções homo oeconomicus e empresário de si.

Na concepção clássica, o homem econômico era considerado um dos parceiros do processo de troca. No neoliberalismo, o homo oeconomicus torna-se um empresário de si mesmo. Conforme expressa Foucault:

considerar o sujeito como homo oeconomicus não implica uma assimilação antropológica de todo comportamento, qualquer que seja, a um comportamento econômico. Quer dizer, simplesmente, que a grade de inteligibilidade que será adotada para o comportamento de um novo indivíduo é essa. Isso quer dizer também que o indivíduo só vai se tornar governamentalizável, que só se vai poder agir sobre ele na medida em que, e somente na medida em que, ele é homo oeconomicus. Ou seja, a superfície de contato entre o indivíduo e o poder que se exerce sobre ele, por conseguinte o princípio de regulação do poder sobre o indivíduo, vai ser essa espécie de grade do homo oeconomicus. O homo oeconomicus é a interface do governo e do indivíduo. E isso não quer dizer de forma alguma que todo indivíduo, todo sujeito, é um homem econômico (FOUCAULT, 2008b, p. 346).

Com essa grade do homo oeconomicus, o empresário de si mesmo, sujeito de uma economia, passa a ser caracterizado como aquele que, por um lado, investe em capital, primordialmente humano, produz seu lucro, otimiza a relação de ganho e perda e, por outro lado, influencia-se por essa relação de seus pares. Esse empresário de si mesmo, como interface do governo e do indivíduo, tem seu comportamento racional capturado e mobilizado por um Estado, um mercado, presente em cada um e em 
todos, sendo que "o homo oeconomicus que se quer reconstituir não é o homem da troca, não é o homem consumidor, é o homem da empresa e da produção (FOUCAULT, 2008b, p. 201). Neste momento, notamos a importância do capital humano para essa racionalidade política.

O capital humano tem como característica primordial, conforme Schultz (1973, p. 53), a de que "é ele parte do homem. É humano porquanto se acha configurado no homem, e é capital porque é uma fonte de satisfações futuras, ou de futuros rendimentos, ou ambas as coisas". Nesse sentido, a educação e a escolarização são tomadas como um investimento e seus resultados uma forma de capital. Com isso, entendemos que, na formação continuada do docente do AEE, existe uma estratégia de produção de uma subjetividade docente e, para tal, as táticas denominadas docência no jogo de cada um e de todos, docência como querer modificar-se e docência como prática solidária voltadas à racionalidade política neoliberal. Isso porque, parafraseando o exposto por Schultz (1973), o Curso de formação continuada em questão pode ser tomado como um investimento e seus resultados como uma forma de capital humano. Então, neste momento, interessa dissertar sobre essa tecnologia de governamento docente na racionalidade política neoliberal, pois, na contemporaneidade, a formação de professores produz o tornar-se professor como um processo contínuo de empresariamento de si mesmo e dos outros, ao modo da empresa. Ainda, por esta lógica, competências, modos e técnicas são organizadas para produzir um modelo ideal de professor do AEE nas salas de recursos multifuncionais.

Através dos programas de formação inicial e continuada, fomentados pela política nacional de formação de professores no nosso País, especificamente, nos vinculados à Diretoria de Políticas de Educação Especial, na Secretaria de Educação Continuada, Alfabetização, Diversidade e Inclusão (SECADI), do Ministério da Educação (MEC), materializamos a Rede Nacional de Formação Continuada de Professores para a Educação Especial, o Projeto Institucional e os Projetos Pedagógicos dos Cursos de Aperfeiçoamento em AEE. Com estes, desenvolvemos a estratégia 
e as táticas do AEE como uma tecnologia de governamento. Ao usar a noção de tecnologia de governamento, situamos esse exercício de problematização na relação entre uma estratégia, entendida como a finalidade, e suas táticas, compreendidas como os meios (CASTRO, 2009), que produzem a condução da conduta do docente do AEE à escola inclusiva.

Nesse sentido, considerando as regulamentações sobre o cadastramento e a seleção de cursos de instituições públicas de ensino superior na Rede Nacional, esta se constitui como "o conjunto de instituições públicas de educação superior ofertante de cursos de formação continuada para professores das redes públicas da educação básica" (BRASIL, 2009a, p. 20). De certa maneira, por meio dessa Rede Nacional, os cursos do AEE, seja na modalidade de aperfeiçoamento/extensão, seja na modalidade de especialização, recebem financiamento e podem ser implementados em âmbito nacional e regional. Assim, mesmo parte de uma unidade nacional, no caso desta prática de pesquisa, optamos em tratar também dos Cursos de Aperfeiçoamento em AEE ofertado pela IFES, do Estado do Rio Grande do Sul, com prazos de integralização que variam, nas cinco edições, entre 120, 180, 190 e 225 horas, a fim de contextualizar a emergência e a operacionalidade dessa formação continuada de professores numa região do nosso País que se tornou, ao longo dos anos, uma referência na formação de educadores especiais nos cursos de graduação e especialização regulares ofertados na Universidade Federal de Santa Maria.

Com essa Rede Nacional, três pressupostos da Educação Inclusiva firmam a importância da formação continuada de professores e da própria criação de uma unidade nacional na produção de uma docência do AEE na escola inclusiva. A Portaria Normativa $n^{\circ} 12$, de 24 de abril de 2007, dispõe sobre a criação do Programa de Formação Continuada de Professores na Educação Especial, com:

$\S$ o crescente ingresso de alunos com necessidades educacionais especiais na rede pública de ensino e o aumento do número de es- 
colas com alunos incluídos nas classes comuns do ensino regular, os professores manifestam a necessidade de formação acerca das necessidades educacionais especiais;

$\S$ a organização tradicional da educação especial de forma paralela ao ensino regular, que evidencia a necessidade de aprofundar os conceitos e conhecimentos visando transformar as práticas pedagógicas para a educação inclusiva, efetivando as mudanças necessárias na escola; $\S$ a carência de formação de professores na área da educação especial que constitui uma barreira para o acesso, a permanência, aprendizagem, participação na escola (BRASIL, 2007, p. 4).

Por meio desses parágrafos do texto legal, evidenciamos os três pressupostos da Educação Inclusiva. No primeiro, os professores manifestam a necessidade de formação acerca das necessidades especiais, entendemos que o texto legal constitui o desejo docente pela formação continuada na Educação Especial como um imperativo no contexto da inclusão dos alunos com necessidades educacionais especiais nas escolas comuns/ regulares. No segundo, a transversalidade da Educação Especial desde a Educação Infantil até o Ensino Superior prevê que, para implementar ações inclusivas na escola regular, se torna necessário efetivar mudanças pedagógicas na organização da educação especial nessa escola. No último parágrafo, a barreira para o acesso, a permanência, aprendizagem, participação na escola, justifica a falta da formação docente para o AEE.

Esses três pressupostos da Educação Inclusiva, na prática de pesquisa em questão - junto às regulamentações da Rede Nacional e do Projeto Institucional -, inscrevem a formação continuada de professores do AEE na racionalidade política neoliberal, na medida em que, como estratégia, propõem a formação de uma determinada docência para dar conta dos limites e das possibilidades da escola inclusiva. Dito de outra maneira, a produção de uma subjetividade docente, um modelo ideal de professor, para uma razão de Estado passa a ser a finalidade dessa formação de professores, dos seus saberes e das suas práticas, à escola inclusiva. Essa razão de Estado, por se colocar como instrumento de inteligibilidade e 
de estratégia nas práticas de condução da conduta docente, possibilita engendrar, em âmbito nacional e regional, o imperativo de estar em atividade e desejar permanecer em atividade, próprio da racionalidade política neoliberal; a produção das redes, das práticas solidárias nessa racionalidade política. Essa estratégia, então, depende da operacionalização de certas táticas, como dissemos anteriormente, dos meios que se desenvolvem para determinada finalidade.

Na primeira tática, "Docência no jogo de cada um e de todos", percebemos que a docência envolve processos de individualização e de totalização, de modo a contemplar ações pedagógicas voltadas ao sujeito com deficiência, transtornos globais do desenvolvimento e altas habilidades/superdotação e também, de forma mais generalista, ao público-alvo da Educação Especial. Dessa forma, a individualização diz respeito às ações pedagógicas desenvolvidas ao nível do próprio indivíduo como, por exemplo, a correção da posição da pelve de um indivíduo com deficiência física como forma de complementar esse desvio - a cifose torácica e a retroversão pélvica - ou a potencialização das "habilidade(s) demonstrada(s) pelo aluno, por meio do enriquecimento curricular previsto no plano de atendimento individual” (DELPRETTO, 2010, p. 23) para suplementar a formação do aluno com altas habilidades/superdotação. Para tal, utilizam-se as verdades científicas, do campo médico, psicológico, pedagógico etc., para justificar essas ações de complementação ou suplementação pedagógicas.

Por sua vez, a totalização parte do entendimento de que "o professor, então, desempenhará o seu papel formador, que não se restringe a ensinar somente a uma parcela dos alunos que conseguem atingir o desempenho exemplar esperado pela escola. Ele ensina a todos, indistintamente (ROPOLI, 2010, p. 14). Assim, o docente do AEE deve ensinar a cada um e a todos, sendo este o público-alvo da Educação Especial. Enquanto cidadãos-ativos materializam um grupo capaz de gerir seus próprios riscos, internos e externos, a noção de público-alvo expressa a ideia de um grupo de risco, de alto risco que, portanto, ne- 
cessita de condução (DEAN, 1999). Neste caso, incluem-se os alunos da Educação Especial que, pela formação continuada de professores do AEE, continuam tendo o diagnóstico, a identificação, a caracterização, a classificação e a hierarquização dos seus perfis como ponto de partida das ações pedagógicas desenvolvidas à gerência do risco e à gestão da segurança nas escolas inclusivas.

Nessas ações pedagógicas interessa não apenas a matrícula, o ingresso, mas a aprendizagem e a participação na escola inclusiva, nas redes de consumo e concorrência próprias da racionalidade política neoliberal. A Rede Nacional e os Cursos em questão preveem, então, conhecimentos, recursos, técnicas e atitudes na formação docente em prol do sujeito e do público-alvo da Educação Especial, em prol dos jogos de consumo e concorrência. O trabalho do professor de AEE passa a consistir "na gestão dos processos de aprendizagem, na avaliação desse processo e em seu acompanhamento" (GOMES, 2010, p. 9).

Na segunda tática, "Docência como querer modificar-se", partimos do ensino e da aprendizagem do desejo de formação continuada pelos professores do AEE. Essa relação entre ensinar e aprender a modificar-se continuamente são elementos veiculados nos Cursos de Aperfeiçoamento em AEE e na Rede Nacional, respectivamente, conforme estratos abaixo:

O Curso de Formação de Professores para o Atendimento Educacional Especializado propõe-se a formar professores com competência pedagógica e metodológica para realizar o atendimento educacional especializado para atuação nas salas de recursos multifuncionais, nas escolas da rede pública (IFES, 2007a, p. 17).

O professor da educação especial não é mais aquele que ensina os alunos com deficiência os conteúdos escolares, e, portanto, a sua formação deve ajudá-lo, agora, a saber, observar a realidade, identificar os problemas ali presentes e ser capaz de trabalhar construindo redes de parcerias, para, então, propor a solução adequada à superação das barreiras que impedem seu aluno de estar na escola e lá aprender, de forma autônoma, instigante e criativa (GIACOMINI, 2010, p. 41-42). 
O primeiro estrato diz respeito ao ensino do desejo de modificar-se continuamente, já o segundo retrata a aprendizagem desse desejo. De uma maneira ou outra, ambos oferecem condições para os professores do AEE desenvolverem as competências pedagógicas, tomadas como o conjunto de habilidades mobilizadas para desenvolver uma prática de ensino e aprendizagem, e as competências metodológicas, relativas aos recursos, às técnicas colocadas em operação para garantir a aprendizagem, importantes às ações pedagógicas nas escolas inclusivas. O querer modificar-se se torna, neste momento, uma forma de capital humano, de investimento no nível do próprio indivíduo, do próprio professor do AEE.

A prática de pesquisa em Educação Especial permite, então, materializar o professor da Educação Especial/ o professor do AEE como aquele que consome os conhecimentos, os recursos, as técnicas e as atitudes para trabalhar na perspectiva da educação inclusiva e, de certa forma, diferencia-se pela formação em AEE dos seus pares nos jogos de concorrência. $\mathrm{O}$ consumo e a concorrência fazem parte desse processo no qual cada docente do AEE deve garantir a participação e a aprendizagem do aluno na escola inclusiva, inclusive, dispondo de recursos e técnicas próprios. Tanto o pedagógico quanto o metodologicamente corretos são ensinados nos Cursos de Aperfeiçoamento do AEE e na Rede Nacional, devendo ser apreendidos e mobilizados pelos empresários de si no cotidiano escolar.

Na terceira tática, "Docência como prática solidária", temos que a materialização de como relações de consumo e concorrência nos processos formativos e na própria atuação do docente do AEE nas escolas inclusivas podem produzir práticas solidárias. Nesse sentido,

A organização de uma sala de aula é atravessada por decisões da escola que afetam os processos de ensino e de aprendizagem. Os horários e rotinas escolares não dependem apenas de uma única sala de aula; o uso dos espaços da escola para atividades a serem realizadas fora da classe precisa ser combinado e sistematizado para o bom aproveitamento de todos; as horas de estudo dos professores devem coincidir 
para que a formação continuada seja uma aprendizagem colaborativa; a organização do Atendimento Educacional Especializado - AEE não pode ser um mero apêndice na vida escolar ou da competência do professor que nele atua (ROPOLI, 2010, p. 10).

A presença de um regime de aprendizagem colaborativa na formação continuada de professores torna-se uma das condições para desenvolver práticas solidárias na escola inclusiva. Essas práticas solidárias, por sua vez, permitem integrar o AEE, entendido como um serviço de complementação ou suplementação da formação dos alunos da Educação Especial, às ações pedagógicas dessa escola. Nesse sentido, justificamos que a solidariedade, inicialmente uma virtude cristã, está implicada com a racionalidade política neoliberal, na medida em que, tomando a noção de Émile Durkheim na leitura de Castel (2009, p. 35), "pacto de solidariedade, pacto de trabalho, pacto de cidadania: pensar as condições da inclusão de todos para que possam comerciar juntos, como se dizia na época do Iluminismo, isto é, 'fazer sociedade"', a dependência entre os sujeitos também ocorre em relação à prática governamental. A escola inclusiva como uma unidade-empresa, além de promover o empresariamento de si e as relações de consumo e concorrência na docência, operacionaliza as práticas solidárias para efetivar o sucesso da inclusão escolar.

Dessa forma, através da Aprendizagem Colaborativa [em Rede] (ACR), derivada de uma proposta metodológica da Aprendizagem Baseada em Problemas e desenvolvida para um programa de formação continuada do AEE, na modalidade a distância, focaliza-se "a aprendizagem colaborativa, o trabalho em equipe, contextualizado na realidade do aprendiz" (ROPOLI, 2010, p. 30) no processo de escolarização dos alunos com deficiências, transtornos globais do desenvolvimento e altas habilidades/superdotação. As redes sociais, as parcerias, as práticas solidárias entre docentes do AEE, docentes da sala regular, famílias, demais profissionais da educação, setores da comunidade, então, são elementos para consolidar essa aprendizagem, essa participação dos sujeitos da 
Educação Especial na escola inclusiva, na sociedade contemporânea. Cada um desses elementos torna-se um parceiro importante à lógica da unidade-empresa, da escola inclusiva e, portanto, de suas relações de consumo e concorrência. Ao mesmo tempo, cada um desses parceiros demonstra competências e atribuições específicas, formas de empresariamento, formas de solidariedade, para operacionalizar a inclusão escolar.

Em relação ao docente da sala regular e ao docente do AEE, considerando o interesse desta prática de pesquisa na formação continuada de professores do AEE, um dos cadernos da Coleção “A Educação Especial na Perspectiva da Inclusão Escolar” expressa que:

Os professores comuns e os da Educação Especial precisam se envolver para que seus objetivos específicos de ensino sejam alcançados, compartilhando um trabalho interdisciplinar e colaborativo. As frentes de trabalho de cada professor são distintas. Ao professor da sala de aula comum é atribuído o ensino das áreas do conhecimento, e ao professor do AEE cabe complementar/suplementar a formação do aluno com conhecimentos e recursos específicos que eliminam as barreiras as quais impedem ou limitam sua participação com autonomia e independência nas turmas comuns do ensino regular (ROPOLI, 2010, p. 19).

Num primeiro momento, nesse estrato, temos a docência especializada, na medida em que ao docente da sala regular cabe o ensino das áreas do conhecimento e, ao docente do AEE, a complementação ou suplementação da formação do aluno com necessidade educacional especial para que ele possa participar da turma comum. Num segundo momento, esse docente do AEE deve partir do trabalho especializado e, em seguida, envolver os colegas e os demais profissionais da educação da escola, bem como ampliar as ações pedagógicas com a parceria de setores específicos do serviço público, da família e de setores da comunidade. Os objetivos, as finalidades da inclusão escolar servem, neste momento, às ações no nível individual e aquelas que devem comprometer e mobilizar todos no processo de inclusão. 
A partir da estratégia de produção de uma subjetividade docente e das táticas "docência no jogo de cada um e de todos", "docência como querer modificar-se" e "docência como prática solidária”, o AEE como tecnologia de governamento produz efeitos na formação continuada de professores do AEE e nas ações pedagógicas desenvolvidas na escola inclusiva. A racionalidade política neoliberal, que engendra o estar e o permanecer nos jogos de consumo e concorrência, perpassa essa escola e os espaços-tempos do AEE. Da mesma maneira, produz essas formas de docência, essas formas de empresariamento e essas formas de solidariedade. Essa prática de pesquisa interessada na condução da conduta docente, perspectiva adotada a partir da noção de governamentalidade, possibilita, então, o exercício de problematização de como a emergência de um Estado governamentalizado, Estado presente e proliferado por esta relação consigo e com os outros, e profundamente vinculado à racionalidade política neoliberal, produz a formação continuada de professores do AEE e a organização da docência às escolas inclusivas.

\section{Prática de pesquisa em Educação Especial: possibilidades}

A partir do desenvolvimento do AEE como uma tecnologia de governamento docente, procuramos materializar, mesmo que de forma sintética, as operações da governamentalidade na pesquisa exposta neste artigo. Nesse sentido, indicamos a produção de uma subjetividade docente como estratégia (finalidade) dessa condução de condutas dos professores do AEE. A docência no jogo de cada um e de todos, a docência como querer modificar-se e a docência como prática solidária foram tratadas no sentido de táticas (meios) dessa tecnologia de governamento, situando-a no contexto das artes de governar, em desenvolvimento desde o século XVI, especificamente da racionalidade política de um Estado governamentalizado. Com isso, a governamentalidade, integrante da analítica de poder da produção foucaultiana, constituiu-se como uma ferramenta analítica operante na formação de professores e nas ações pedagógicas escolares. 
Desse modo, o interesse na governamentalidade não derivou da teoria que seria aplicada à prática de pesquisa. Pelo contrário, retirada da caixa de ferramentas de Foucault, a governamentalidade foi colocada em operação para fazer funcionar o que temos no terreno da escolarização brasileira, de modo a problematizar o lugar de verdade do AEE nas políticas públicas de Educação Especial, na formação continuada de professores e nas escolas inclusivas. A governamentalidade, como ferramenta analítica, teve importância na prática de pesquisa desenvolvida neste artigo na medida em que operou no exercício analítico empreendido, exercício este circunscrito na zona cinza, no interstício da Educação Especial na perspectiva da Educação Inclusiva.

Nessa operação da governamentalidade na zona cinza, evitamos tomar as políticas e as práticas da educação inclusiva, da formação de professores como boas ou ruins. Isso traria meramente o emprego de um juízo de valor, tática muito frágil diante dos efeitos dessas políticas e práticas na vida dos sujeitos com necessidades educacionais especiais, dos professores do AEE. Dessa forma, tomamos essas políticas como um dispositivo biopolítico, a formação dos professores do AEE como uma tecnologia de governamento e as escolas inclusivas como capazes de materializar a gerência do risco e a gestão da segurança em relação a cada aluno, ao público-alvo da Educação Especial. Efetivamos, portanto, um exercício de problematização, de inspiração genealógica, primordial na prática de pesquisa para, na zona cinza, tomar a governamentalidade como uma proposta de análise das relações de poder.

\section{Referências}

BRASIL. Ministério da Educação e do Desporto. Secretaria de Educação Especial. Política Nacional de Educação Especial. Brasília, 1994.

. Conselho Nacional de Educação. Câmara de Educação Básica. Parecer n. 13, de 03 de junho de 2009. Diretrizes Operacionais para o atendimento educacional especializado na Educação Básica, modalidade 
Educação Especial. Diário Oficial [da] República Federativa do Brasil, Brasília, DF, 24 set. 2009a. Disponível em: http://portal.mec.gov.br/dmdocuments/pceb013_09_homolog.pdf. Acesso em: 07 dez. 2010.

. Conselho Nacional de Educação. Câmara de Educação Básica. Resolução no 4, de 2 de outubro de 2009. Institui Diretrizes Operacionais para o Atendimento Educacional Especializado na Educação Básica, modalidade Educação Especial. Diário Oficial [da] República Federativa do Brasil, Brasília, DF, 05 out. 2009b. Disponível em: http://portal.mec. gov.br/dmdocuments/rceb004_09.pdf. Acesso em: 07 dez. 2010.

BRASIL. Decreto ${ }^{\circ}{ }^{7}$ 7611, de 17 de novembro de 2011. Dispõe sobre a educação especial, o atendimento educacional especializado e dá outras providências. Diário Oficial [da] República Federativa do Brasil, Brasília, DF, 18 nov. 2011. Disponível em: http://www.in.gov.br/imprensa/ visualiza/index.jsp?jornal $=1000 \&$ pagina $=5 \&$ data $=18 / 11 / 2011$. Acesso em: 29 out. 2011.

BRASIL. Edital no 1, de 2 de março de 2009. Chamada Pública para Cadastramento e Seleção de Cursos de Instituições Públicas de Educação Superior para a Rede de Formação Continuada de Professores na Educação Especial no âmbito do Sistema Universidade Aberta do Brasil - UAB. Diário Oficial [da] República Federativa do Brasil,Brasília, DF, 04 mar. 2009. Disponível em: http://www.in.gov.br/imprensa/visualiza/index.jsp?jornal $=3 \&$ pagina $=20 \&$ data $=04 / 03 / 2009$. Acesso em: 29 out. 2011.

Ministério da Educação. Secretaria de Educação Especial. Política Nacional de Educação Especial na Perspectiva da Educação Inclusiva. In:Inclusão: Revistada Educação Especial,Brasília, v. 04, n. 01, p. 09-17, jul./dez. 2008.

. Portaria Normativa $\mathrm{n}^{\mathrm{o}} 12$, de 24 de abril de 2007. Dispõe sobre a criação do "Programa de Formação Continuada de Professores na Educação Especial". Diário Oficial [da] República Federativa do Brasil, Brasília, DF, 26 abr. 2007. Disponível em: http://www.in.gov.br/ imprensa/visualiza/index.jsp?jornal $=1$ \&pagina $=4 \& d a t a=26 / 04 / 2007$. Acesso em: 29 out. 2011. 
CASTEL, Robert. As metamorfoses da questão social: uma crônica do salário. Petrópolis: Vozes, 2009. 611p.

CASTRO, Edgardo Manuel. Vocabulário de Foucault: um percurso pelos seus temas, conceitos e autores. Tradução Ingrid Muller Xavier. Revisão Técnica Alfredo Veiga-Neto e Walter Omar Kohan. Belo Horizonte: Autêntica, 2009. 480p.

DEAN, Mitchell. Governmentality: power and rule in modern society. London: Sage, 1999.

DELPRETTO, Bárbara Martins de Lima et al. Altas habilidades/superdotação.Brasília: Ministério da Educação, Secretaria de Educação Especial, Universidade Federal do Ceará, 2010. 27p. (Coleção A Educação Especial na Perspectiva da Inclusão Escolar)

FOUCAULT, Michel. Em defesa da sociedade. Curso dado no Collège de France (1975-1976). Tradução de Maria Ermantina Galvão. São Paulo: Martins Fontes, 2005. 382 p. (Coleção tópicos)

Segurança, território e população. Curso dado no Collège de France (1977-1978). Tradução de Eduardo Brandão. São Paulo: Martins Fontes, 2008a. 572 p. (Coleção tópicos)

- Nascimento da biopolítica. Curso dado no Collège de France (1978 - 1979). Tradução de Eduardo Brandão. São Paulo: Martins Fontes, 2008b. 474 p. (Coleção tópicos)

. Microfísica do poder. Organização e tradução de Roberto Machado. Rio de Janeiro: Edições Graal, 2001. 295 p.

GIACOMINI, Lília et al. Orientação e mobilidade, adequação postural e acessibilidade espacial. Brasília: Ministério da Educação, Secretaria de Educação Especial, Universidade Federal do Ceará, 2010. 44p. (Coleção A Educação Especial na Perspectiva da Inclusão Escolar)

GOMES, Adriana Leite Lima Verde et al. O atendimento educacional especializado para alunos com deficiência intelectual. Brasília: Minis- 
tério da Educação, Secretaria de Educação Especial, Universidade Federal do Ceará, 2010. 28p. (Coleção A Educação Especial na Perspectiva da Inclusão Escolar)

INSTITUIÇÃO FEDERAL DE ENSINO SUPERIOR. Fundamentos para a Implementação de uma política pública de formação continuada de professores na área da educação especial, na modalidade a distância, para serem implementados pelo MEC, através da SEESP. Santa Maria, p. 05-28. 2007a.

LOPES, Maura Corcini; VEIGA-NETO, Alfredo. Inclusão e governamentalidade. Revista Educação e Sociedade, Campinas, v. 28, n. 100, p. 947-963, Out. 2007. Edição Especial.

LUNARDI, Márcia Lise. A produção da anormalidade surda nos discursos da educação especial. 2003. 200 f. Tese (Doutorado em Educação) - Universidade Federal do Rio Grande do Sul, Porto Alegre, 2003.

ROPOLI, Edilene Aparecida et al. A escola comum inclusiva. Brasília: Ministério da Educação, Secretaria de Educação Especial, Universidade Federal do Ceará, 2010. 48p. (Coleção A Educação Especial na Perspectiva da Inclusão Escolar)

SCHULTZ, Theodore William. O capital humano: investimentos em educação e pesquisa. Tradução de Marco Aurélio de Moura Matos. Rio de Janeiro: Zahar Editores, 1973. 250 p.

TRAVERSINI, Clarice Salete. Programa alfabetização solidária: o governamento de todos e de cada um. 2003. 210 p. Tese (Doutorado em Educação) - Universidade Federal do Rio Grande do Sul, Porto Alegre, 2003.

Data de registro: $21 / 10 / 2014$

Data de aceite: 15/09/2015 